\title{
Consumer's sensory perception of food attributes: A survey on flavor
}

\author{
Farjana Rahman Bhuiyan ${ }^{1}$, Abu Torab MA Rahim ${ }^{2}$ \\ ${ }^{1}$ Biochemistry and Cell Biology, Bangladesh University of Health Sciences, Dhaka, Bangladesh \\ ${ }^{2}$ Institute of Nutrition and Food Science, University of Dhaka, Dhaka, Bangladesh
}

Email address:

farjanarb@yahoo.com (F. R. Bhuiyan), torabrahim@gmail.com (A. T. M. Rahim)

\section{To cite this article:}

Farjana Rahman Bhuiyan, Abu Torab MA Rahim. Consumer's Sensory Perception of Food Attributes: A Survey on Flavor. Journal of Food and Nutrition Sciences. Special Issue: Food Processing and Food Quality. Vol. 3, No. 1-2, 2015, pp. 157-160.

doi: $10.11648 /$ j.jfns.s.2015030102.40

\begin{abstract}
Consumer's sensory perception of food attributes plays a vital role in food preference. Sensory responses to the flavor (taste and aroma), color, and texture of food are determinants of individual food choices. A descriptive cross-sectional survey on perception of food attributes was conducted on 400 respondents (aged $\leq 40$ years) to evaluate consumers' perception of flavoral attributes and perceived role of chosen foods in a healthy diet. The data were collected through face to face interviews of the respondent using a pretested structured questionnaire. A non-probability sampling method was used for the survey. Among the 400 respondents, 200 were males and the rest 200 were females with majority as students (40\%). The consumers were found facing difficulty in perceiving the technical terms for attributes of foods but when different Bangla vocabulary denoting flavoral attributes was used then the respondents felt comfortable in understanding. About $41 \%$ of the preferred the Bangla word 'Shadgondho' to understand the concept of flavor. The correct perception of flavor ( $p=0.054$ ) was not much dependent on the profession of respondents, but there was an association between their perception level and selection of preferred foods $(\mathrm{p}=0.018)$. Majority of the respondents $(85.3 \%)$ preferred the food attribute 'fruity flavor' in selecting their foods for consumption. The respondents treated their chosen foods on flavoral attributes as menial to lunch or dinner and usually ate them as snacks. About one fourth of the respondents have higher sensory perception level and food preference ability. However, in combination with other food attributes like color and texture, this association needs further investigations.
\end{abstract}

Keywords: Sensory Perception, Consumer's Preference, Food Attributes, Flavor

\section{Introduction}

Sensory responses to the taste, aroma, colour, and texture of foods help determine food preferences and eating habits. However, sensory responses alone cannot take as sole predictor of food choice. In reality, there are multiple links between taste perceptions, taste preferences and food preferences; food choices and amount of food consumed.

According to Lund et al, consumers are readily able to assess three major food attributes, namely texture, flavor and appearance ${ }^{1}$. Even though flavor is frequently judged as the most important food characteristic ${ }^{2,3}$. According to Murphy et al, the identification of pureed foods using only taste and odor cues does not always produce the correct answer. When the possibility to use odor cues is also removed, the task becomes even more difficult ${ }^{4}$. In some foods, texture may be the most important food attribute. This is likely to happen if the food has a bland flavor or has crisp characteristics ${ }^{5}$.

Flavor is a complex sense which can be defined as an amalgam of taste (taste buds on the tongue), aroma (the olfactory epithelium in the nose), pain/irritation/hotness (trigeminal sensors in the mouth and nose) and mouthfeel (force sensors in the mouth). The signals from these sensors are processed both locally and centrally in the brain to yield a pattern that we associate with the flavor of a particular food ${ }^{6}$. Since the sensations of aroma, taste and the trigeminal sense are difficult to locate and separate analytically when eating, the term 'flavor' is used to accommodate these perceptions. Flavor perception, in most cases, is time dependent; as food changes during eating because of many different factors, like salivation and mastication ${ }^{7}$.

The flavor of food is one of the key factor determining food quality and acceptance. Like the West, food industries of Bangladesh should also give due importance to the sensory responses of the consumers towards new food 
products. But first of all, the sensory perception of food attributes of Bangladeshi consumers should be investigated. A number of studies from our laboratory investigated consumers' perception, attitude, belief, and intake behaviour of food and food components ${ }^{8-11}$. The present study, to our best of knowledge, first on this kind was undertaken to investigate the perception and preference towards flavor targets of foods of urban Bangladeshi consumers.

\section{Methods}

A descriptive cross-sectional survey on perception of food attributes was conducted with 400 respondents, mainly students who were doing their study on different schools, colleges and university, such as Home Economics College, Eden College, Dhaka City College, Dhaka Women College, Mirpur University College, Mirpur Ideal College, and Mirpur Bangla College, residing at Dhanmondi, Mirpur, Uttora, Mugda, and Kafrul areas of Dhaka city. A number of graduate and post graduate service holders working in various organizations in Dhaka were also included in the study.

The data was obtained through personal interviews of each respondent on structured questionnaire including both open and close ended questions. The sociodemographic information about the respondents was also designed to collect through the questionnaire. By incorporating specific questions about knowledge of, attitude toward, and perception and preferences of foods of the respondents were collected. A non-probability sampling method was used for the survey. A pretest survey conducted among respondents of $10 \%$ of the sample size using the draft questionnaire. It facilitated to finalize the questionnaire in its practically useable form. The final questionnaire was developed carefully in terms of forms and sequence so that it can meet the study objectives successfully. The questionnaire was consisting of two parts. Part A was confined the questions relating to the socio-demographic feature. Part B was included questions relating to the respondents knowledge of, attitude toward, and perception and preferences of foods.

Descriptive statistics was reported as percentages using whole numbers. The Chi-squire test was used to evaluate correlation between dependent and independent variables of the study population. Significance level was set at 0.05 . Microsoft Excel worksheet was used to construct contingency tables followed by cross table statistics with the statistical package SPSS, version 11.5.

\section{Results and Discussion}

Nutrition education and intervention strategies aimed at improving population diets ought to consider sensory pleasure response to foods, in addition to a wide range of demographic and sociocultural variables. Besides, food industries in Bangladesh are now a visible sector of industrial development. New food products are always coming in the trays of the food shops. Since, all people have their likes and dislikes and self believes about food, many people show specific preference and conservativeness about selecting foods. Like food industries in the developed countries, local food industries should also give due importance to the sensory responses of the consumers toward new food products.

The sensory perception of flavoral attribute of food and food products of the consumers was selected for investigation The reasons are many folds: first, traditional snack food intake is a stable component of our food behaviour; second, fast food culture is booming in our society; third, more and more people are skipping regular meals (lunch or dinner); fourth, our urban populations seem to be converging on a pattern of diet high in saturated fat, sugar, and refined foods and low in fiber - often termed the 'Western diet'. These characteristics of the urban consumers emphasized the need of various non-conventional, ready-to-eat food and food products. Foods available in the market, therefore, need to evaluate whether they meet the sensory pleasures of the consumers. Flavor is the most desirable quality and contributes to our enjoyment of foods.

The relevant socio-demographic characteristics of the study participants presented in Table-1, shows that majority of the respondents were students $(40 \%)$ and a large portion of the respondents were from middle income group (40\%).

Table 1. Socio-demographic features of the respondents $(n=400)$

\begin{tabular}{ll}
\hline Variable & Percentage (No. of respondents) \\
\hline Sex & \\
Male & $50(200)$ \\
Female & $50(200)$ \\
Age & \\
$10-18$ & $12(48)$ \\
$18-\leq 40$ & $74.8(299)$ \\
$>40$ & $13.3(53)$ \\
Education & \\
Below S.S.C & $6.0(24)$ \\
S.S.C & $8.5(34)$ \\
H.S.C & $23.0(92)$ \\
Graduation & $33.0(132)$ \\
Above graduation & $27.0(108)$ \\
Others & $2.5(10)$ \\
Profession & \\
Students & $40.0(160)$ \\
Teacher & $8.5(34)$ \\
Govt. Service & $8.0(32)$ \\
Non govt. Service & $23.8(95)$ \\
Business & $8.5(34)$ \\
Housewife & $7.3(29)$ \\
Others & $4.0(16)$ \\
Monthly Family Income (in tk) & \\
$<10000$ & $26.8(107)$ \\
10001-20000 & $38.3(153)$ \\
$>$ 20000 & $35.0(140)$ \\
\hline &
\end{tabular}

When respondents were asked to mention their perception of flavor, considerable number of them showed preference (41\%) towards the Bangla word 'Shad-gondho' to understand what is meant for flavor to them. They also used other Bangla vocabulary to denote flavor of food. As flavor is a combination of taste, smell and feel $^{6}$, we used some Bangla 
vocabularies used to denote flavor. Among these, 'Shadgondho' is accurate to express the notion of flavor and therefore, considered 'the correct answer' for any question related to flavor. Accordingly, the correct answer by the respondents to denote their perception of flavor $(p=0.054)$ was found not much dependent on the profession of the respondents. On the other hand, there was an association between their perception level and selection preference of food $(p=0.018)$. Majority of the respondents $(85.3 \%)$ preferred the food attribute 'fruity flavor' in selecting their foods for consumption. Consumers treated these foods as 'off meal' menial other than lunch or dinner and they ate them at different times of the day.

Table 2. Relationship between sex and respondent perception of flavor

\begin{tabular}{|c|c|c|c|c|c|c|c|c|c|c|}
\hline \multirow[b]{2}{*}{ Sex } & \multicolumn{8}{|c|}{ Respondents perception of food in using Bangla vocabulary to denote it } & \multirow[b]{2}{*}{ Total } & \multirow[b]{2}{*}{ p value } \\
\hline & Shugondho & Shurov & Shadgondho & Ghran & Khushbu & Shad & $\begin{array}{l}\text { Nakae } \\
\text { Shovouneo }\end{array}$ & Beshesh gondho & & \\
\hline \multirow{2}{*}{ Male } & $27.5 \%$ & $6.5 \%$ & $38.5 \%$ & $4.5 \%$ & $3.5 \%$ & $7.0 \%$ & $2.5 \%$ & $10.0 \%$ & $100 \%$ & \multirow{5}{*}{0.134} \\
\hline & $(55)$ & $(13)$ & (77) & (9) & (7) & $(14)$ & (5) & $(20)$ & (200) & \\
\hline \multirow{2}{*}{ Female } & $20.0 \%$ & $5.0 \%$ & $43.0 \%$ & $10.5 \%$ & $5.5 \%$ & $4.0 \%$ & $1.5 \%$ & $10.5 \%$ & $100 \%$ & \\
\hline & $(40)$ & (10) & (83) & (21) & (11) & (8) & (3) & (21) & (200) & \\
\hline Total & $23.8 \%$ & $5.8 \%$ & $40.8 \%$ & $7.5 \%$ & $4.5 \%$ & $5.5 \%$ & $2.0 \%$ & $10.3 \%$ & $100 \%$ & \\
\hline
\end{tabular}

$\mathrm{x}^{2}=11.106 ; \mathrm{df}=7$

Table 3. Relationship between profession and respondents' perception of flavor

\begin{tabular}{llll}
\hline \multirow{2}{*}{ Profession } & \multicolumn{2}{c}{ Distribution of correct and incorrect flavor perception of the respondents } \\
\cline { 2 - 3 } & Correct & Partial Correct & Incorrect \\
\hline Student & $48.8 \%(78)$ & $36.8 \%(59)$ & $14.4 \%(23)$ \\
Teacher & $29.4 \%(10)$ & $58.9 \%(20)$ & $11.8 \%(4)$ \\
Govt. Service & $46.9 \%(15)$ & $40.8 \%(13)$ & $12.6 \%(4)$ \\
Non Govt. service & $35.8 \%(34)$ & $48.5 \%(46)$ & $15.8 \%(15)$ \\
Business & $35.3 \%(12)$ & $58.8 \%(20)$ & $5.9 \%(2)$ \\
House wife & $31.2 \%(9)$ & $65.4 \%(19)$ & $3.4 \%(1)$ \\
Others & $31.3 \%(5)$ & $68.7 \%(11)$ & 0.054 \\
\hline
\end{tabular}

$\mathrm{X}^{2}=40.783 ;$ d.f. $=35$

Table 4. Association between flavor perception and flavor preference of the respondents

\begin{tabular}{|c|c|c|c|c|c|}
\hline \multirow{2}{*}{ Perception of flavor } & \multicolumn{4}{|c|}{ How much preference of flavor } & \multirow{2}{*}{ p value } \\
\hline & High & Medium & Little & No & \\
\hline Correct & $57.8 \%(96)$ & $36.7 \%(61)$ & $5.4 \%(9)$ & - & \\
\hline Partial Correct & $46.9 \%(90)$ & $41.7 \%(80)$ & $9.9 \%(19)$ & $1.6 \%(3)$ & 0.018 \\
\hline Incorrect & $31.0 \%(13)$ & $54.8 \%(23)$ & $14.3 \%(6)$ & - & \\
\hline
\end{tabular}

$X^{2}=11.314 ;$ d.f. $=6$

Table 5. Choice of flavor by the respondents $(n=400)$

\begin{tabular}{|c|c|c|c|}
\hline \multirow[t]{2}{*}{ Type of flavor } & \multicolumn{3}{|c|}{$\begin{array}{l}\text { Choice level } \\
\text { [Percentage (No. of respondents)] }\end{array}$} \\
\hline & High Choice & Dislike & Medium Choice \\
\hline Fruity & $85.3(341)$ & $3.5(14)$ & $11.3(45)$ \\
\hline Milky & $50.3(201)$ & $24.3(97)$ & $25.5(102)$ \\
\hline Spicy & $45.3(181)$ & $25.5(102)$ & 29.3 (117) \\
\hline Vegetable & $56.3(225)$ & $16.3(65)$ & $27.5(110)$ \\
\hline Cereal & $30.5(122)$ & $33.0(132)$ & $36.5(146)$ \\
\hline Beverage & $51.5(206)$ & $20.8(83)$ & 27.8 (117) \\
\hline Fish & $52.8(211)$ & $24.8(99)$ & $22.5(90)$ \\
\hline Meaty & $56.8(227)$ & $18.5(74)$ & $24.8(99)$ \\
\hline Oily & $14.3(57)$ & $49.1(196)$ & $36.8(147)$ \\
\hline Egg & $42.0(168)$ & 28.5 (114) & 29.5 (118) \\
\hline Floral & $26.5(106)$ & $43.3(173)$ & $30.3(121)$ \\
\hline
\end{tabular}

\section{Conclusion}

One fourth of study respondents showed correct perception of flavor which guided them to choose correctly the foods with flavor attributes they liked for. However, in combination with other food attributes like color and texture, this association needed to be evaluated in further studies.

\section{References}

[1] Lund, D. 1982. Quantifying reactions influencing quality of foods: texture, flavor and appearance. Journal of Food Processing and Preservation, 6, 133-153.70.

The resultant food preference patterns have a number of intrinsic factors; age is one of them. But it is always difficult to capture the dynamics of food preference of the young adults. Other factors that affect the flavor preferences include eating situation and the time of the day.

[2] Schutz, H. G. and Wahl, O. L. 1981. Consumer perception of the relative importance of appearance, flavor and texture to food acceptance. In: Criteria for Food Acceptance. How Man Chooses What He Eats. J. Solm, and R. L. Hall (eds.) Forster Publishing Ltd. Switzerland. p. 97-116. 
[3] Moskowitz, H. R. and Krieger, B. 1995. The contribution of sensory liking to overall liking: an analysis of six food categories. Food Quality and Preference, 6, 83-90.

[4] Murphy, C. 1985. Cognitive and chemosensory influences on age-related changes in the ability to identify blended foods. Journal of Gerontology, 40, 47-52.

[5] Szczesniak, A. S. and Kahn, E. L. 1971. Consumer awareness of and attitudes to food texture. I: Adults. Journal of Texture Studies, 2, 280-295.

[6] Lillian Hoagland Meyer, 2002; Food chemistry.

[7] Taylor, A. J. and Linforth, R. S. T. 1996. Flavour release in the mouth. Trends in Food Science and Technology, 7, 444-448.
[8] Rahim ATMA, Chowdhury R, 2005. Perceived Role of Dietary Fiber in Healthy Diet and its intake pattern among educated urban population, Bang J Nutr; 18-19, 61-68.

[9] Bhuyan MAH, Rahim ATMA, Hossain AMMM, and Shaheen N, 2004. Food behavior and nutritional status of the Dhakaiyyah population. South Asian J Nutr.

[10] Rahim ATMA and Bhuyan MAH, 1995. Students' perception towards the fattening and dieting foods. $\mathrm{J}$ Asiat Soc Bangladesh, Sci: 21(2): 233-41.

[11] Rahim ATMA, Aziz F, Shaheen S, and Bhuyan MAH, 2001. Perception and preference of fast food and traditional snack food by selected urban population. Bangladesh J Physiol Pharmacol; 17(2): 58-62. 